\title{
Serotonin Neuronal Function from the Bed to the Bench: Is This Really a Mirrored Way?
}

\author{
(1) Adeline Etievant, ${ }^{1}$ (1) Thorsten Lau, ${ }^{2,3,4}$ Guillaume Lucas, ${ }^{5}$ and Nasser Haddjeri ${ }^{6}$
}

https://doi.org/10.1523/ENEURO.0021-19.2019

\begin{abstract}
${ }^{1}$ Integrative and Clinical Neurosciences EA481, University of Bourgogne Franche-Comté, Besançon F-25000, France, ${ }^{2}$ Department of Translation Brain Research, Central Institute for Mental Health, Medical Faculty Mannheim, Heidelberg University, ${ }^{3}$ HITBR Hector Institute for Translational Brain Research gGmbH, Mannheim J5 68159, Germany, ${ }^{4}$ German Cancer Research Center (DKFZ), Heidelberg INF280, Germany, ${ }^{5}$ Institut National de la Santé et de la Recherche Médicale, University of Bordeaux, Neurocentre Magendie, Physiopathologie de la Plasticité, Neuronale, Unité 1215, Bordeaux F-33000, France, and ${ }^{6}$ Univ Lyon, Université Claude Bernard Lyon 1, Inserm, Stem Cell and Brain Research Institute U1208, Bron F-69500, France
\end{abstract}

Key words: firing activity; induced neurons; induced pluripotent stem cells; reprogramming; serotonin; translation

\section{Significance Statement}

Induced pluripotent stem cells (iPSCs) offer a great opportunity to recapitulate both normal and pathologic development of brain tissues. Recently, three research teams have developed human-PSC technology and direct somatic cell reprogramming to allow induction of human serotonin (5-hydroxytryptamine; 5-HT) neurons in vitro. While preclinical studies have repeatedly shown that $5-\mathrm{HT}$ suppresses $5-\mathrm{HT}$ neuronal firing activity, one group has tested the effect of 5-HT on the neuronal activity of those 5-HT-like cells and found a paradoxical excitatory action of $5-\mathrm{HT}$. Here, we argue that few cautions in translational interpretations have to be taken into account. Nonetheless, using patient-derived cells for generating disease relevant cell types truly offers a new and powerful approach for investigating mechanisms playing fundamental roles in psychiatric disorders.

Disease modeling by direct reprogramming into desired cell types represents a new huge challenge. Induced pluripotent stem cells (iPSCs), cells reprogrammed from human somatic cells, offer a great opportunity to recapitulate both normal and pathologic development of brain

Received January 16, 2019; accepted May 2, 2019; First published May 22, 2019.

The authors declare no competing financial interests.

Author contributions: A.E., T.L., G.L., and N.H. designed research; A.E., T.L., G.L., and N.H. performed research; A.E., T.L., G.L., and N.H. analyzed data; A.E., T.L., G.L., and N.H. wrote the paper.

This work was supported by "Région Auvergne-Rhône-Alpes SCUSI 2018" (Grant R18119CC).

Acknowledgements: We thank Renaud Rovera and Sarah Delcourte for providing helpful comments on this manuscript.

Correspondence should be addressed to Nasser Haddjeri at nasser.haddjeri@inserm.fr.

https://doi.org/10.1523/ENEURO.0021-19.2019

Copyright (C) 2019 Etievant et al.

This is an open-access article distributed under the terms of the Creative Commons Attribution 4.0 International license, which permits unrestricted use, distribution and reproduction in any medium provided that the original work is properly attributed. tissues and may as well provide essential strategies toward cell-based therapy of neuropsychiatric diseases (Vadodaria et al., 2018). Successfully, in 2016, three research teams have developed human-PSC technology (Lu et al., 2016) and direct somatic cell reprogramming (Vadodaria et al., 2016a; Xu et al., 2016) to allow induction of human serotonin neurons in vitro for the first time (for review, see Vadodaria et al., 2016b).

Remarkably, Lu et al. (2016) have demonstrated the accurate timely regulation of WNT, SHH, and FGF4 signaling pathways during the serotonergic $(5-\mathrm{HT})$ neuron differentiation and generated an enriched population of $5-\mathrm{HT}$ neurons from human embryonic stem cells (ESCs) and iPSCs. These human 5-HT neurons not only express specific biomarkers (TPH2, 5-HT, GATA3, GATA2, FEV, LMX1B, SERT, AADC, and VMAT2) but also show electrophysiological activities and release 5-HT in response to stimuli in a dose-dependent and time-dependent manner (Lu et al., 2016). Subsequently, this group further analyzed the features of human iPSCs-derived 5-HT neurons both in vitro and in vivo. They found that these human $5-\mathrm{HT}$ 
neurons are sensitive to the specific neurotoxin 5,7dihydroxytryptamine in vitro. After being transplanted into new-born mice, the cells not only expressed their typical molecular markers but also showed the migration and projection to the cerebellum, hindbrain, and spinal cord. Clearly, the obtained human iPSCs-derived neurons exhibit the typical features of the 5-HT neurons in the brain (Cao et al., 2017). As observed in vivo, a recent study also described selective serotonin reuptake inhibitor (SSRI)dependent elevation of extracellular 5-HT concentrations, caused by the antidepressant citalopram exposure of human iPSC-derived 5-HT neurons (Vadodaria et al., 2019).

Accordingly, somatic cells were also shown to be directly converted to functional neurons (directly induced neurons) through ectopic expression of neural conversion factors. Consequently, dopaminergic, cholinergic, or striatal medium spiny neurons have been recently generated directly from human fibroblasts by using forced expression of lineage-specific transcription factors acting during brain development (Miskinyte et al., 2017). Therefore, Xu et al. (2016) demonstrated the efficient conversion of human fibroblasts to serotonin induced neurons following expression of the transcription factors Ascl1, Foxa2, Lmx1b, and FEV. The authors have examined the transdifferentiation that was enhanced by p53 knock-down and suitable culture conditions (including hypoxia, which was shown to increase the yield of 5-HT neurons). Importantly, $\mathrm{Xu}$ et al. (2016) verified that serotonin induced neurons were able to express markers for mature 5-HT neurons, presented $\mathrm{Ca} 2+-$ dependent $5-\mathrm{HT}$ release and selective 5-HT uptake, and exhibited spontaneous action potentials and spontaneous excitatory postsynaptic currents. Surprisingly however, bath application of 5-HT significantly increases the firing rate of spontaneous action potentials. In parallel, Vadodaria et al. (2016a) showed that overexpressing a different combination of 5-HT phenotype-specific transcription factors (NKX2.2, FEV, GATA2, and LMX1B) in combination with the neuronal transcription factors ASCL1 and NGN2 directly and efficiently generated 5-HT neurons from human fibroblasts. Induced 5-HT neurons showed increased expression of specific serotonergic genes known to be expressed in raphe nuclei and displayed spontaneous action potentials, released serotonin in vitro and functionally responded to SSRIs.

Noticeably, the results from $\mathrm{Xu}$ and co-workers on the functional effect of 5-HT on spontaneous action potentials of induced 5-HT neurons appear to be in discrepancy with all the preclinical data obtained so far. Indeed, animal studies, mostly conducted in rodents, have demonstrated that this neurotransmitter exerts an inhibitory influence on the firing activity of mature 5-HT neurons (for review, see Blier and El Mansari, 2013). 5-HT neurons exist in nearly all animal taxa, from the invertebrate nervous system to mammalian brains. The 5-HT system in the vertebrate brain is implicated in various behaviors and diseases. In mammals, the cell bodies of 5-HT neurons are located in the brainstem, near or on the midline. The dorsal raphe nucleus (DRN) contains $\sim 50 \%$ of the total 5 -HT neurons in both rat and human CNS (Piñeyro and Blier 1999). In rodents, the $5-\mathrm{HT}$-containing cells have been shown to exhibit a slow (1-2 Hz) and regular firing rate, with a long-duration positive action potential. This regular discharge pattern results from a pacemaker cycle attributed to a $\mathrm{Ca}^{2+}$-dependent $\mathrm{K}^{+}$outward current. The depolarization is followed by a long afterhyperpolarization (AHP) period, which diminishes slowly during the interspike interval. During the depolarization, extracellular $\mathrm{Ca}^{2+}$ enters the neuron via a voltage-dependent $\mathrm{Ca}^{2+}$ channel activating $\mathrm{a} \mathrm{K}^{+}$outward conductance leading to an AHP. $\mathrm{Ca}^{2+}$ is then sequestered/extruded and the AHP diminishes slowly. When the membrane potential reaches the lowthreshold $\mathrm{Ca}^{2+}$ conductance, a new action potential is triggered (Piñeyro and Blier 1999). Around five decades ago, Aghajanian et al. (1970) were the first to assess, electrophysiologically in anesthetized rodents the effects of monoamine oxidase inhibitors (MAOIs), the first class of antidepressant medications, on the firing activity of single, serotonin-containing neurons of the midbrain raphe nuclei. All MAOI tested caused depression of raphe unit firing rate by increasing endogenous 5-HT and such suppressant effects were prevented by prior treatment with an inhibitor of 5-HT synthesis. Similarly, in vitro and in vivo, direct application of exogenous 5-HT suppresses 5-HT neuronal firing activity (Piñeyro and Blier 1999). Numerous rodent studies have shown that this net effect of 5-HT is mediated via the activation of somatodendritic 5- $\mathrm{HT}_{1 \mathrm{~A}}$ autoreceptors (for review, see Piñeyro and Blier 1999). This $5-\mathrm{HT}_{1 \mathrm{~A}}$ autoreceptor receives an increased activation by endogenous 5-HT at the beginning of a treatment with a SSRI or a MAOI and, consequently, a decreased 5-HT neuronal firing activity is obtained. Indeed, when activated by $5-\mathrm{HT}, \mathrm{G}_{\alpha \mathrm{i} / \mathrm{o}}$-coupled $5-\mathrm{HT}_{1 \mathrm{~A}}$ autoreceptors trigger a strong reduction of 5-HT impulse flow through the opening of inwardly rectifying $\mathrm{K}^{+}$channels and the inhibition of voltage-dependent $\mathrm{Ca}^{2+}$ channels (Piñeyro and Blier 1999). By reducing pacemaker firing, $5-\mathrm{HT}_{1 \mathrm{~A}}$ autoreceptors regulate $5-\mathrm{HT}$ levels both locally in the DRN and in terminal projection regions (Courtney and Ford, 2016). As the SSRI or MAOI treatment is prolonged, the $5-\mathrm{HT}_{1 \mathrm{~A}}$ autoreceptor desensitizes and firing activity is restored in the presence of the SSRI or MAOI. This adaptive change has been proposed to underlie, at least in part, the delayed therapeutic effect of SSRI or MAOI in major depression (Piñeyro and Blier 1999). However, only very few studies have been conducted in humans to directly address the role of $5-\mathrm{HT}_{1 \mathrm{~A}}$ autoreceptors on 5-HT neuronal activity. One of the reasons resides in the small size of the DRN, which renders it virtually invisible for MRI-based in vivo imaging studies (Sibon et al., 2008). Interestingly still, human EEG studies have reported that the stimulation of presynaptic $5-\mathrm{HT}_{1} \mathrm{~A}$ receptors induces a shift of the frequency spectrum (McAllister-Williams and Massey, 2003), an effect reflecting the inhibitory action of these receptors on 5-HT activity (Seifritz et al., 1996, 1998). More recently, clinical studies have shown that the $5-\mathrm{HT}_{1 \mathrm{~A}}$ agonist buspirone produces a more pronounced shift in medication-free depressed patients, confirming the hypothesis that at 
least some depressive disorders may be related to an abnormally enhanced functional status of $5-\mathrm{HT}_{1 \mathrm{~A}}$ autoreceptors, leading to a hypo-function of the 5-HT system (McAllister-Williams et al., 2014). Also of note, several PET studies have shown that an enhanced binding potential at DRN 5- $\mathrm{HT}_{1 \mathrm{~A}}$ sites correlates with a reduced 5- $\mathrm{HT}$ transmission within the amygdala, thus providing indirect, but strong evidence, that these receptors inhibit terminal 5-HT release (Fisher et al., 2006). Clearly, the reason of the discrepant electrophysiological findings mentioned above appears to be puzzling. For that reason, the net effect of 5-HT on spontaneous action potentials of induced 5-HT neurons, obtained from both Lu et al. (2016) and Vadodaria et al. (2016a), should be extremely interesting to be assessed and compared. Indeed, a role of the chosen transcription factors for this opposing electrophysiological result cannot be fully ruled out (Vadodaria et al., 2018). The different combinations of transcription factors employed may cause differential maturation stages of induced $5-\mathrm{HT}$ neurons. In rodent, the $5-\mathrm{HT}_{1 \mathrm{~A}}$ autoreceptor-mediated inhibition was shown to vary with age and was absent/reduced until Postnatal 21 (Rood et al., 2014). Xu and co-workers employed the transcription factor Ascl1, involved in rostral and caudal neurogenesis of 5-HT neurons, Foxa2, activated by sonic hedgehog signaling to induce 5-HT neuronal fate by suppression of ventral motor neuron generation, as well as Fev and $L m x 1 b$, which are essential for the expression of the 5-HT neurochemical phenotype (Kiyasova and Gaspar, 2011). In contrast to this, Vadodaria and co-workers established generation of induced 5-HT neurons by overexpression of the 5-HT phenotype-specific transcription factors Fev, Lmx1b, Gata2, and Nkx2.2. The latter being discussed as having a cluster-specific function in 5-HT neurogenesis (Kiyasova and Gaspar, 2011). Therefore, an excitatory action of 5-HT may reflect differential maturation stages of induced 5-HT neurons, and in vitro maturation may be enhanced by forced expression of a larger number of neuronal and 5-HT specific transcription factors. Actually, a thorough examination of the supplementary data provided by Xu et al. (2016) indicates that even when considered mature (i.e., $>46 \mathrm{~d}$ old), their induced 5-HT neurons display a resting membrane potential remaining as high as $-42 \mathrm{mV}$, a value quite remote from those classically measured in vivo in preclinical studies, i.e., below $-60 \mathrm{mv}$ (Liu et al., 2002). Another possibility would reside in the fact that the protocol chosen by $\mathrm{Xu}$ and co-workers triggered a modified maturation of $5-\mathrm{HT}_{1 \mathrm{~A}}$ autoreceptors, leading to an alternative coupling of these receptors and preventing them to activate the $\mathrm{G}_{\alpha \mathrm{i} / \mathrm{o}}$ subunit. In this context, the use of Patch-Seq (Fuzik et al., 2016), a recent method for obtaining full transcriptome data from single cells after whole-cell patch-clamp recordings of induced 5-HT neurons, should be very helpful to provide critical clues of these paradoxical electrophysiological results. Finally, it has to be kept in mind that in vivo, 5-HT neurons are part of a mature circuitry that obviously cannot be fully recapitulated in vitro, which might also impair the efficacy of $5-\mathrm{HT}_{1 \mathrm{~A}}$ autoinhibition.
Alternatively, the discrepancy between the results of $\mathrm{Xu}$ et al. (2016), and those observed in rodents may be related to a differential sensitivity toward distinct kinds of 5-HT autoregulation. Indeed, it has recently been proposed that $5-\mathrm{HT}_{2 \mathrm{~B}}$ receptors may constitute a new class of autoreceptors that would actually be excitatory, therefore counteracting the influence of the $5-\mathrm{HT}_{1 \mathrm{~A}}$ ones (Belmer et al., 2018). In mice, this positive autoregulation appears to be negligible with respect to the $5-\mathrm{HT}_{1 \mathrm{~A}^{-}}$ related autoinhibition, requiring the use of specific $5-\mathrm{HT}_{2 \mathrm{~B}}$ agonists to be unmasked (Belmer et al., 2018). It remains possible that the induced $5-\mathrm{HT}$ neurons obtained by $\mathrm{Xu}$ et al. (2016), express a higher proportion of $5-\mathrm{HT}_{2 \mathrm{~B}}$ receptors, rendering the net influence of 5-HT positive on them. Thus, it would be very informative to assess the excitatory action exerted by 5-HT on the spontaneous action potentials of these cells with both selective $5-\mathrm{HT}_{1 \mathrm{~A}}$ and $5-\mathrm{HT}_{2 \mathrm{~B}}$ receptor antagonists. If this latter hypothesis were to be confirmed, the next step would be to determine whether such a higher expression of $5-\mathrm{HT}_{2 \mathrm{~B}}$ receptors constitutes a distinct feature of human $5-\mathrm{HT}$ neurons, or whether it results from the technique of induction.

In summary, even if several advantages and inconvenients can be addressed in the use of iPSCs versus induced neurons, in terms of cell source, time and cost efficiency as well as expendability (Mertens et al., 2018), all three groups have provided, the same year, important and robust data on the conversion of human cells to induced 5-HT neurons (Lu et al., 2016; Vadodaria et al., 2016a; Xu et al., 2016). In opposition to the electrophysiological results of Xu et al. (2016), preclinical studies have repeatedly shown that $5-\mathrm{HT}$ suppresses $5-\mathrm{HT}$ neuronal firing activity. Significantly, this inhibitory action of 5-HT is frequently related to the well described therapeutic delay of antidepressant action, has been recurrently considered as a "brake" of the antidepressant response and has initiated numerous studies on the development of new and effective therapeutic strategies (Artigas et al., 2017). Furthermore, learning more about the electrophysiological properties of human iPSC-derived 5-HT neurons will not only help to understand serotonergic autoregulation, but also significantly contribute to understanding $5-\mathrm{HT}$ neuromodulation of neuronal circuits. Even if few cautions in translational interpretations have to be taken into account, as for data obtained in animal studies, using patientderived cells for generating disease relevant cell types truly offers a new and powerful approach for investigating the genetic and cellular mechanisms that may play fundamental roles in psychiatric disorders (Vadodaria et al., 2018).

\section{References}

Aghajanian GK, Graham AW, Sheard MH (1970) Serotonincontaining neurons in brain: depression of firing by monoamine oxidase inhibitors. Science 169:1100-1102.

Artigas F, Schenker E, Celada P, Spedding M, Lladó-Pelfort L, Jurado N, Núñez M, Santana N, Troyano-Rodriguez E, Riga MS, van den Munkhof $H$, Castañé $A$, Shaban $H$, Jay TM, Tripathi $A$, Godsil BP, Sebban C, Mariani J, Faure P, Takkilah S, Hughes ZA, et al. (2017) Defining the brain circuits involved in psychiatric disorders: IMI-NEWMEDS. Nat Rev Drug Discov 16:1-2. 
Belmer A, Quentin E, Diaz SL, Guiard BP, Fernandez SP, Doly S, Banas SM, Pitychoutis PM, Moutkine I, Muzerelle A, Tchenio A, Roumier A, Mameli M, Maroteaux L (2018) Positive regulation of raphe serotonin neurons by serotonin $2 \mathrm{~B}$ receptors. Neuropsychopharmacology 43:1623-1632.

Blier P, El Mansari M (2013) Serotonin and beyond: therapeutics for major depression. Philos Trans R Soc Lond B Biol Sci 368: 20120536.

Cao L, Hu R, Xu T, Zhang ZN, Li W, Lu J (2017) Characterization of induced pluripotent stem cell-derived human serotonergic neurons. Front Cell Neurosci 11:131.

Courtney NA, Ford CP (2016) Mechanisms of 5-HT1A receptormediated transmission in dorsal raphe serotonin neurons. J Physiol 594:953-965.

Fisher PM, Meltzer CC, Ziolko SK, Price JC, Moses-Kolko EL, Berga SL, Hariri AR (2006) Capacity for 5-HT1A-mediated autoregulation predicts amygdala reactivity. Nat Neurosci 9:1362-1363.

Fuzik J, Zeisel A, Máté Z, Calvigioni D, Yanagawa Y, Szabó G, Linnarsson S, Harkany T (2016) Integration of electrophysiological recordings with single-cell RNA-seq data identifies neuronal subtypes. Nat Biotechnol 34:175-183.

Kiyasova V, Gaspar P (2011) Development of raphe serotonin neurons from specification to guidance. Eur J Neurosci 34:1553-1562.

Liu RJ, Van den Pol AN, Aghajanian GK (2002) Hypocretins (orexins) regulate serotonin neurons in the dorsal raphe nucleus by excitatory direct and inhibitory indirect actions. J Neurosci 22:94539564.

Lu J, Zhong X, Liu H, Hao L, Huang CT, Sherafat MA, Jones J, Ayala M, Li L, Zhang SC (2016) Generation of serotonin neurons from human pluripotent stem cells. Nat Biotechnol 34:89-94.

McAllister-Williams RH, Massey A (2003) EEG effects of buspirone and pindolol: a method of examining $5-\mathrm{HT} 1 \mathrm{~A}$ receptor function in humans. Psychopharmacology 166:284-293.

McAllister-Williams RH, Alhaj HA, Massey A, Pankiv J, Reckermann U (2014) Somatodendritic 5-hydroxytryptamine1A (5-HT1A) autoreceptor function in major depression as assessed using the shift in electroencephalographic frequency spectrum with buspirone. Psychol Med 44:767-777.

Mertens J, Reid D, Lau S, Kim Y, Gage FH (2018) Aging in a dish: iPSC-derived and directly induced neurons for studying brain aging and age-related neurodegenerative diseases. Annu Rev Genet 52:271-293.

Miskinyte G, Devaraju K, Grønning Hansen M, Monni E, Tornero D, Woods NB, Bengzon J, Ahlenius H, Lindvall O, Kokaia Z (2017)
Direct conversion of human fibroblasts to functional excitatory cortical neurons integrating into human neural networks. Stem Cell Res Ther 8:207-225.

Piñeyro G, Blier P (1999) Autoregulation of serotonin neurons: role in antidepressant drug action. Pharmacol Rev 51:533-591.

Rood BD, Calizo LH, Piel D, Spangler ZP, Campbell K, Beck SG (2014) Dorsal raphe serotonin neurons in mice: immature hyperexcitability transitions to adult state during first three postnatal weeks suggesting sensitive period for environmental perturbation. J Neurosci 34:4809-4821.

Seifritz E, Moore P, Trachsel L, Bhatti T, Stahl SM, Gillin JC (1996) The 5-HT1A agonist ipsapirone enhances EEG slow wave activity in human sleep and produces a power spectrum similar to 5-HT2 blockade. Neurosci Lett 209:41-44.

Seifritz E, Gillin JC, Rapaport MH, Kelsoe JR, Bhatti T, Stahl SM (1998) Sleep electroencephalographic response to muscarinic and serotonin1A receptor probes in patients with major depression and in normal controls. Biol Psychiatry 44:21-33.

Sibon I, Benkelfat C, Gravel P, Aznavour N, Costes N, Mzengeza S, Booij L, Baker G, Soucy JP, Zimmer L, Descarries L (2008) Decreased [18F]MPPF binding potential in the dorsal raphe nucleus after a single oral dose of fluoxetine: a positron-emission tomography study in healthy volunteers. Biol Psychiatry 63:1135-1140.

Vadodaria KC, Mertens J, Paquola A, Bardy C, Li X, Jappelli R, Fung L, Marchetto MC, Hamm M, Gorris M, Koch P, Gage FH (2016a) Generation of functional human serotonergic neurons from fibroblasts. Mol Psychiatry 21:49-61.

Vadodaria KC, Marchetto MC, Mertens J, Gage FH (2016b) Generating human serotonergic neurons in vitro: methodological advances. Bioessays 38:1123-1129.

Vadodaria KC, Ji Y, Skime M, Paquola AC, Nelson T, Hall-Flavin D, Heard KJ, Fredlender C, Deng Y, Elkins J, Dani K, Le AT, Marchetto MC, Weinshilboum R, Gage FH (2019) Altered serotonergic circuitry in SSRI-resistant major depressive disorder patientderived neurons. Mol Psychiatry. Advance online publication. Retrieved May 22, 2019. doi:10.1038/s41380-019-0377-5.

Vadodaria KC, Stern S, Marchetto MC, Gage FH (2018) Serotonin in psychiatry: in vitro disease modeling using patient-derived neurons. Cell Tissue Res 371:161-170.

Xu Z, Jiang H, Zhong P, Yan Z, Chen S, Feng J (2016) Direct conversion of human fibroblasts to induced serotonergic neurons. Mol Psychiatry 21:62-70. 